\title{
Teresa Kowalska, Mieczyslaw Sajewicz and Joseph Sherma (Eds): Chromatographic Techniques in the Forensic Analysis of Designer Drugs
}

\author{
Edward R. Adlard ${ }^{1}$ \\ (c) Springer-Verlag GmbH Germany, part of Springer Nature 2019
}

the start of the main topic of the book-chromatographic analysis of designer drugs and is followed by a further 17 chapters covering various aspects of drug analysis.

The contents of the book are divided into two sectionsthe first dealing with techniques (mainly chromatography with a number of exceptions) and the second dealing with specific compounds/mixtures apart from the final chapter on TLC which appears to be a valedictory in honour of Sherma, well known for his work on TLC over the years, and would have been more appropriate in Section 1.

The title of a book is the ultimate short summary of its contents so it is something of an anomaly that many of the chapters in Section 1 have little or no chromatographic content and it would have been more accurate if the book's title was just "Techniques in the Forensic Analysis...." There is nothing wrong with these chapters; it is just that they are not as covered by the title.

Dismissing my editorial quibbles, this is a book which should be of value to all those interested in drug analysis in general and specifically in illicit drug analysis.

Publisher's Note Springer Nature remains neutral with regard to jurisdictional claims in published maps and institutional affiliations.
Edward R. Adlard

e.adlard77@btinternet.com

1 Burton, UK 